\title{
Left ventricular internal flow fraction from cardiac magnetic resonance images is higher in patients who respond to cardiac resynchronization therapy
}

\author{
Stephanie Clement-Guinaudeau ${ }^{1 *}$, Jonathan Suever ${ }^{2}$, Antonello D'Andrea ${ }^{3}$, Frits Prinzen ${ }^{4}$, Michael Lloyd $^{1}$, \\ Angel R Leon ${ }^{1}$, John N Oshinski ${ }^{1,2}$
}

From 15th Annual SCMR Scientific Sessions

Orlando, FL, USA. 2-5 February 2012

\section{Summary}

Despite the guidelines for patient selection for cardiac resynchronization therapy (CRT), one third of the patients do not benefit from the therapy. We show that internal flow fraction (IFF), an MRI-based dyssynchrony measure, was higher in responders to CRT than the non-responders. Therefore, IFF could be a useful to select patients who will response to CRT.

\section{Background}

One third of the patients selected by the standard criteria to receive a cardiac resynchronization therapy (CRT) do not positively respond by clinical or functional outcome parameters. A large scar burden by late Gadolinium enhancement cardiac magnetic resonance (CMR) has been associated with non-response to CRT. However, CMR parameters, which predict response in nonischemic patients by CMR are limited, or are complex to employ.

Internal Flow Fraction (IFF) is a novel parameter determined from cine images, which measures the fraction of flow over the cardiac cycle that sloshes between the walls of the LV (due to dyssynchronous contraction) compared to the blood that is ejected. It represents an image-based assessment of the amount of non-useful work (not contributing to ejection fraction) done during LV contraction. The purpose of this study was to evaluate whether IFF is higher in patients that positively response to CRT compared to non-responders to CRT.

Emory University, Atlanta, GA, USA

Full list of author information is available at the end of the article

\section{Methods}

38 non-ischemic patients who met criteria for CRT were included in the study. Patients came from three centers (Emory University (Atlanta, USA), Maastricht University (Maastricht, NL), Second University of Naples (Naples, IT)). CMR was obtained pre-CRT on 1.5T MRI systems. Global IFF was determined from short-axis cine SSFP images using an in-house developed MATLAB program. Clinical response to CRT was assessed by the decrease in the NYHA class at 6-month follow-up.

\section{Results}

In our patient group, $66 \%$ of patients were positive responders. In the responders, the average IFF at baseline was significantly higher than in the non-responders group $(0.26 \pm 0.09$ vs. $0.48 \pm 0.2, \mathrm{p}=0.027)$, Figure 1 .

\section{Conclusions}

IFF is higher in patients who respond positively to CRT than non responders. Therefore, IFF could be a useful tool to predict which patients will benefit from the CRT.

\section{Funding}

This study was funded by a grant-in-aid from the American Heart Association.

\section{Author details \\ ${ }^{1}$ Emory University, Atlanta, GA, USA. ${ }^{2}$ Georgia Institute of Technology, Atlanta, GA, USA. ${ }^{3}$ Second University of Naples, Naples, Italy. ${ }^{4}$ Maastricht University, Maastricht, Netherlands.}

Published: 1 February 2012 


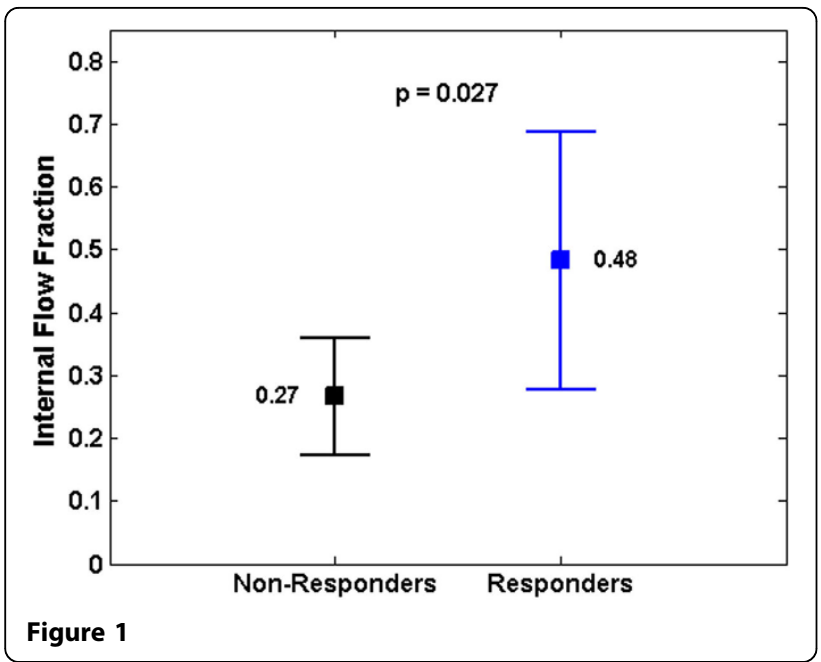

doi:10.1186/1532-429X-14-S1-P216

Cite this article as: Clement-Guinaudeau et al:: Left ventricular internal

flow fraction from cardiac magnetic resonance images is higher in

patients who respond to cardiac resynchronization therapy. Journal of

Cardiovascular Magnetic Resonance 2012 14(Suppl 1):P216.

Submit your next manuscript to BioMed Central and take full advantage of:

- Convenient online submission

- Thorough peer review

- No space constraints or color figure charges

- Immediate publication on acceptance

- Inclusion in PubMed, CAS, Scopus and Google Scholar

- Research which is freely available for redistribution

Submit your manuscript at www.biomedcentral.com/submit
C Biomed Central 